\title{
DETERMINATION OF THERMODYNAMIC STABILITY OF FeB MONOBORIDE
}

\author{
N.Yu. Filonenko ${ }^{1 *}$, A.N. Galdina ${ }^{2}$ \\ ${ }^{1}$ State Institution "Dnipropetrovsk Medical Academy of the Ministry of Health of Ukraine”, Dnipro, \\ Ukraine \\ ${ }^{2}$ Oles Honchar Dnipro National University, Dnipro, Ukraine \\ *e-mail: natph2016@gmail.com
}

In this paper we investigate the phase composition and phase transformations in the Fe-B system alloys with boron content in the range of 9.0-15.0 wt.\%. We use microstructural, X-ray diffraction, differential thermal and durometric analyzes to determine the physical properties of the alloys. The experimental findings show that in the as-cast alloy structure there is $\mathrm{Fe}_{5} \mathrm{~B}_{3}$ phase in small quantities along with $\mathrm{FeB}$ monoboride and $\mathrm{Fe}_{2} \mathrm{~B}$ boride. The $\mathrm{Fe}_{5} \mathrm{~B}_{3}$ phase is formed as a result of the peritectic reaction $\mathrm{L}+\mathrm{FeB} \rightarrow \mathrm{Fe}_{5} \mathrm{~B}_{3}$ at the temperature of $1680 \mathrm{~K}$. The eutectic transformation $\mathrm{L} \rightarrow \mathrm{Fe}_{5} \mathrm{~B}_{3}+\mathrm{Fe}_{2} \mathrm{~B}$ occurs in the boron concentration range of 8.8-10.5 wt.\%. After annealing of the Fe-B alloys at the temperature of $1473 \mathrm{~K}$ and cooling with the rate of $10^{2} \mathrm{~K} / \mathrm{s}$ we observe the occurring of the $\mathrm{Fe}_{5} \mathrm{~B}_{3}$ phase. To spot an opportunity of the secondary monoboride formation in the alloys under consideration, we calculate the thermodynamic characteristics of stability of the system.

Accounting for the contribution of the first degree approximation of high-temperature expansion of thermodynamic potential of $\mathrm{FeB}$ iron monoboride in a $\mathrm{Fe}-\mathrm{B}$ binary alloy enables us to study its thermodynamic stability. It is shown that stability decrease of $\mathrm{FeB}$ at $1423 \mathrm{~K}$ allows suggesting that at this temperature the phase transformation occurs and this fact correlates to the differential thermal analysis results.

Keywords: Fe-B alloys; FeB iron monoboride; thermodynamic stability.

Received 01.11.2019; Received in revised form 11.12.2019; Accepted 23.12.2019

\section{Introduction}

Nowadays the equilibrium state diagram of Fe-B system is available in the literature. Study of Fe-B alloys with boron content within the range from 9.0 wt.\% to 16.0 wt.\% conditioned by the practical use in strengthening the surface of alloys is of particular importance. Many literature sources show the state diagram of the Fe-B system, in which the $\mathrm{FeB}$ monoboride primary crystals are formed from the liquid, and $\mathrm{Fe}_{2} \mathrm{~B}$ iron boride appears as a result of the peritectic reaction. But there is another opinion that the formation of the eutectics $\mathrm{FeB}+\mathrm{Fe}_{2} \mathrm{~B}$ from the liquid takes place. It is known, that in the Fe-B system alloys at boron content of more than $8.86 \mathrm{wt} . \%$ at temperature of $1882 \mathrm{~K}$ in the process of liquid and iron monoboride interaction the peritectic transformation $\mathrm{L}+\mathrm{FeB} \leftrightarrow \mathrm{Fe}_{2} \mathrm{~B}$ occurs, in consequence of which the $\mathrm{Fe}_{2} \mathrm{~B}$ iron boride formation takes place [1]. The authors of [2, 3] suggested that in Fe-B alloys FeB iron monoboride appeared; the compound can exist in two modifications: high-temperature $\beta-\mathrm{FeB}$ and low-temperature $\alpha-\mathrm{FeB}$ formed as a result of the polymorphic transformation $\beta-\mathrm{FeB} \rightarrow \alpha-\mathrm{FeB}$ at the temperature of $1405 \mathrm{~K}$. The Mössbauer data analysis shows that $\beta$ - and $\alpha-\mathrm{FeB}$ have the same magnetization and Curie temperatures $\mathrm{T}_{\mathrm{c}}=580 \mathrm{~K}[2,3]$. Moreover, the authors of these studies pointed out that carbon, aluminum, and other impurities, which contained in furnace charge in the process of fabricating alloys, had a strong influence on the formation of FeB phase. Investigations by K.I. Portnoy [4] revealed the existence of the only modification of iron monoboride with B27 structure. It is known, that carbon has a low solubility in iron monoboride [5-7]. Additionally, doping of FeB system alloys with carbon to $0.2 \mathrm{wt} . \%$ practically does not change the alloy structure [8], and with increase of carbon content the formation of $\mathrm{Fe}_{3}(\mathrm{CB})$ boron cementite takes place.

The authors of Ref. [9] showed that there are no FeB phase in the alloys with boron content up to 10.9 wt.\% at high cooling rate, whereas in the alloys with boron content in the interval of 8.8-10.9 wt.\% the $\mathrm{Fe}_{2} \mathrm{~B}$ phase occurs in the microstructure. In [9] it is stated that in the $\mathrm{Fe}-\mathrm{B}$ alloy with boron content of $8.8 \mathrm{wt} . \% \mathrm{Fe}_{2} \mathrm{~B}$ boride melts at the temperature of 
$1678 \mathrm{~K}$, and at $1660 \mathrm{~K}$ and boron content of $10.9 \mathrm{wt} . \%$ there is the eutectics $\mathrm{Fe}_{2} \mathrm{~B}+\mathrm{FeB}$. The authors of [10] carried out the comparative analysis of the transition metals diagrams and boron. For example, comparing the diagram obtained by E. Kneeller and Y. Khan [9] to the Co-B diagram [11] and to the results of studying thermodynamic functions of the phases for the $\mathrm{Fe}-\mathrm{B}$ alloys, one concludes that in the $\mathrm{Fe}-\mathrm{B}$ system alloys there are the eutectics $\mathrm{L} \rightarrow \mathrm{FeB}+\mathrm{Fe}_{2} \mathrm{~B}$ at the temperature of $1657 \mathrm{~K}$.

There is also another point of view concerned with transformation in Fe-B alloys at $1400 \mathrm{~K}$, namely during the isothermal holding within the temperature interval of 1400 $1500 \mathrm{~K}$ and rapid aftercooling the formation of metastable $\mathrm{Fe}_{5} \mathrm{~B}_{3}$ boride phase, possibly, takes place at boron content of 11.0-15.0 wt.\%, but the mechanism of formation, area of the state diagram of Fe-B system, and thermodynamic functions of this phase are not determined [12]. Despite the fact that structural, mechanical, and chemical properties of Fe-B system alloys are under study for decades, the question of phase composition and phase transformations in these alloys remains topical.

The purpose of this work is to determine the phase transformations in the Fe-B alloys with boron content within the range from $9.0 \mathrm{wt} . \%$ to $16.0 \mathrm{wt} . \%$, and examine the mechanism of the $\mathrm{Fe}_{5} \mathrm{~B}_{3}$ phase formation and the thermodynamic stability of this phase.

\section{Materials and methods}

The investigation was performed on specimens with boron content of 9.015.0 wt.\%, the rest is iron. To obtain these alloys we used the furnace charge of such content: metal (with content of 99.99 wt.\%), amorphous boron (with boron content of 97.5 wt.\%). The smelting of specimens was carried out in Tammann furnace with graphite heater in alundum crucibles in argon atmosphere. The cooling rate of alloys was $10 \mathrm{~K} / \mathrm{s}$. To determine the chemical composition of alloy, we used the chemical and spectroscopic analysis. The microhardness of the phases was measured by means of microhardness gauge PMT-3.

The phase composition of alloys was determined by means of X-ray microanalysis with JSM-6490 microscope, as well as by means of optical microscope "Neophot-21". Xray electron probe analysis was performed using internal standards. The X-ray structure analysis was performed with diffractometer DRON-3 in monochromated $\mathrm{Fe}-\mathrm{K}_{\alpha}$ radiation.

\section{Results and discussion}

The microstructure of Fe-B alloys in the as-cast condition at boron content within the range of 9.0-15.0 wt.\% contains rounded dendrites of $\mathrm{FeB}$ phase located in solid solution based on $\mathrm{Fe}_{2} \mathrm{~B}$ boride (Fig. 1). FeB iron monoboride has different coloring patterns in the process of microstructure study by optical microscope: white, shades of gray and black (Fig. 2, a).

The authors of [13] suggested that white FeB monoborides corresponded to hightemperature modification of $\beta-\mathrm{FeB}$ and black ones - to low-temperature $\alpha-\mathrm{FeB}$. The authors explained their findings by incompleteness of peritectic reaction resulted in the formation of $\mathrm{Fe}_{2} \mathrm{~B}$ boride when the liquid interacted with iron monoboride.

It should be noted that in dark-colored monoborides, according to the results of microstructure analysis, there was decomposition and, according to the results of X-ray diffraction analysis, this alloy consists of such phases: $\mathrm{FeB}$ iron monoboride, $\mathrm{Fe}_{5} \mathrm{~B}_{3}$ boride, and $\mathrm{Fe}_{2} \mathrm{~B}$ boride. The results of the durometric analysis show that the microhardness of iron monoboride takes different values depending on the color. Thus, white in color monoboride has microhardness of $24.05 \mathrm{GPa}$, and black-colored one $21.8 \mathrm{GPa}$. The microhardness of the solid solution based on $\mathrm{Fe}_{2} \mathrm{~B}$ iron boride is $20.01 \mathrm{GPa}$. In addition, the white-colored monoboride is less fragile than the black one. 


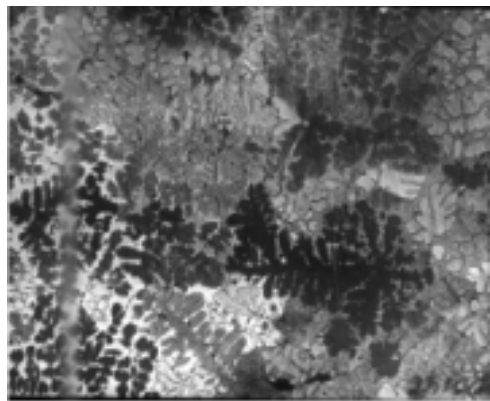

Fig. 1. Microstructure of Fe-B alloy with boron content of 13.0 wt.\%.

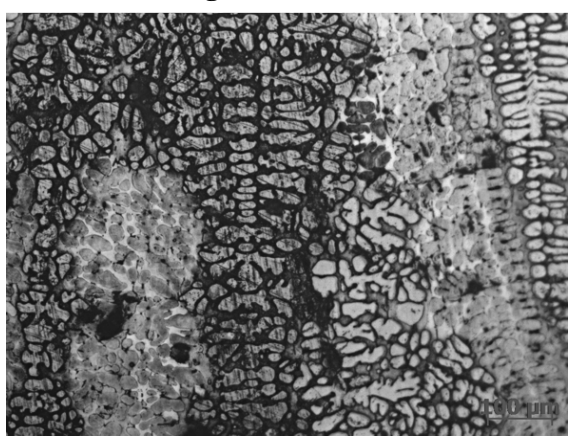

a

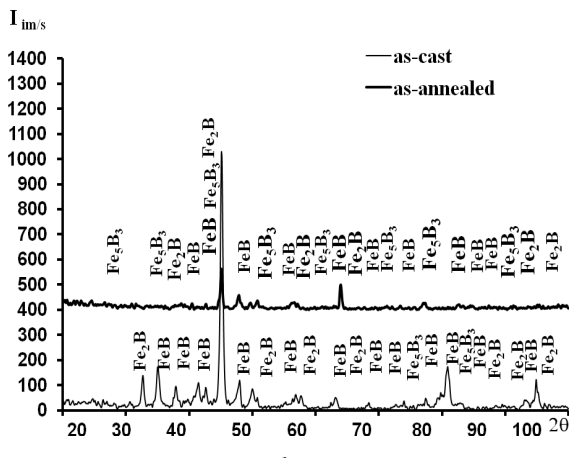

b

Fig. 2. Microstructure, $\times 100$ (a), and diffractograms (b) of alloy with boron content of $13.0 \mathrm{wt} \%$ after annealing at $1473 \mathrm{~K}$ for 4 hours and cooling with the rate of $10^{2} \mathrm{~K} / \mathrm{s}$.

The presence of monoborides of different colors with distinct physical properties in the structure of alloys can be explained by the fact that in the process of grinding the fracture of monoboride dendrites takes place. This phenomenon is associated with the fact that in monoboride structure there are [001] and [100] planes, in which there are no boron atoms at all [14-15], but this explanation is not sufficient to substantiate the processes occurring in these alloys.

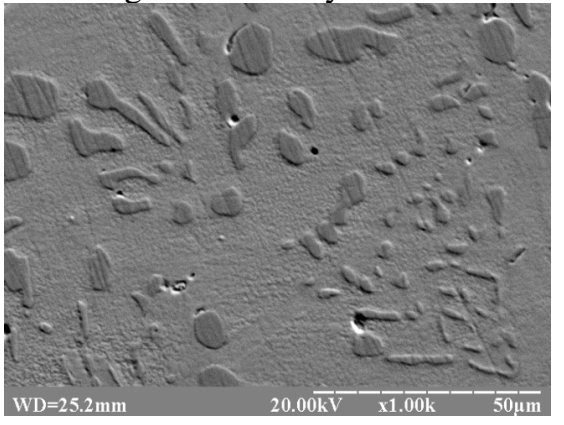

a

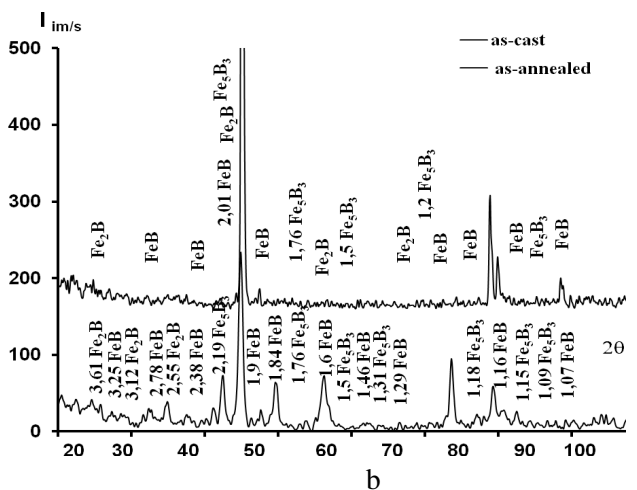

Fig. 3. As-cast microstructure (a), and as-cast and as-annealed diffractograms (b) of Fe-B alloy with boron content of $10.0 \mathrm{wt} . \%$.

In order to reveal the phase transitions in Fe-B alloy, the differential thermal analysis was performed. According to its results, in iron-based alloy with boron content of $10.0 \mathrm{wt} . \%$, the phase transformation $\mathrm{L} \rightarrow \mathrm{FeB}$ occurs while cooling at the temperature of $1809 \mathrm{~K}$. The formation of $\mathrm{Fe}_{5} \mathrm{~B}_{3}$ boride is possible as a result of the peritectic reaction 
of $\mathrm{L}+\mathrm{FeB} \leftrightarrow \mathrm{Fe}_{5} \mathrm{~B}_{3}$ at the temperature of $1680 \mathrm{~K}$. At the temperature of $1411 \mathrm{~K}$ an insignificant thermal effect was observed in the thermogram, that may indicate the phase transformation $\mathrm{Fe}_{5} \mathrm{~B}_{3} \rightarrow \mathrm{FeB}+\mathrm{Fe}_{2} \mathrm{~B}$ occurring in solid state. Thus, the formation of $\mathrm{Fe}_{5} \mathrm{~B}_{3}$ phase takes place at the temperature of $1680 \mathrm{~K}$ as a result of the peritectic reaction $\mathrm{L}+\mathrm{FeB} \rightarrow \mathrm{Fe}_{5} \mathrm{~B}_{3}$, and the decomposition $\mathrm{Fe}_{5} \mathrm{~B}_{3} \rightarrow \mathrm{FeB}+\mathrm{Fe}_{2} \mathrm{~B}$ arises at $1420 \mathrm{~K}$.

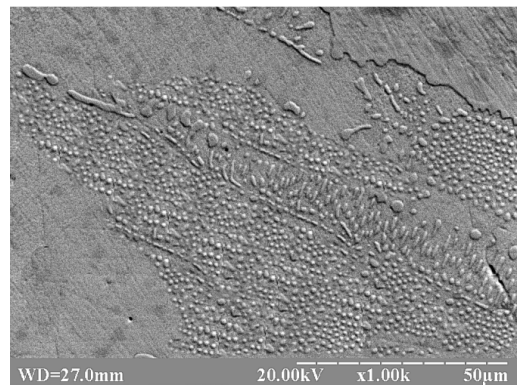

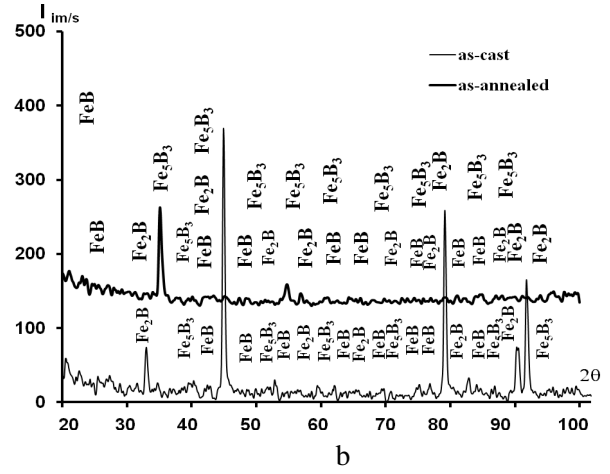

Fig. 4. Fe-B alloy with boron content of $9.3 \mathrm{wt} . \%$ : microstructure (a) after annealing at $1473 \mathrm{~K}$ for 4 hours and after cooling with the rate of $10^{2} \mathrm{~K} / \mathrm{s}$; as-cast and as-annealed diffractograms (b).

As it is shown in [16], the formation of $\mathrm{Fe}_{5} \mathrm{~B}_{3}$ boride occurs at the temperature of $1680 \mathrm{~K}$, which correlates with data obtained in this paper, and at the temperature of $1420 \mathrm{~K}$ the phase transformation resulting in the formation of secondary monoboride $\mathrm{FeB}$ is possible. To verify the possibility of phase transformations at the temperature of $1420 \mathrm{~K}$, the specimens of alloys with boron content of $9.0-16.0 \mathrm{wt} . \%$ were heated to the temperature of $1473 \mathrm{~K}$ for four hours and cooled with the rate of $10^{2} \mathrm{~K} / \mathrm{s}$.

The microstructure of as-cast alloy with boron content of $13.0 \mathrm{wt} . \%$ was represented by monoboride and iron boride. The microstructure of alloy with boron content of 13.0 wt.\% after annealing and further cooling represented by two phases, iron monoboride and $\mathrm{Fe}_{2} \mathrm{~B}$ boride, was, at first glance, in agreement with common point of view. After annealing at $1473 \mathrm{~K}$ and cooling at the rate of $10^{2} \mathrm{~K} / \mathrm{s}$, the phase composition changes. The primary crystals of $\mathrm{FeB}$ monoboride observed in a matrix, which was represented by $\mathrm{Fe}_{5} \mathrm{~B}_{3}$, and decomposition of this phase into two phases, monoboride and $\mathrm{Fe}_{2} \mathrm{~B}$ boride, were testified by the results of X-ray diffraction analysis (Fig. 2). According to the results of microspectral analysis, after annealing the content of boron in alloys in $\mathrm{FeB}$ phase was 15.85 wt.\% and in $\mathrm{Fe}_{2} \mathrm{~B}$ boride it was 7.65 wt.\%.

Our investigation of microhardness of the constituents enabled us to obtain the following results: after annealing the microhardness of white-colored monoborides was 23.06 GPa, and that of dark-colored monoborides was $17.22 \mathrm{GPa}$, for phase decomposition it was $27.93 \mathrm{GPa}$. So, for alloys with boron content of $13.0 \mathrm{wt} \%$ the microstructure after casting is represented by the phases: monoboride, as well as $\mathrm{Fe}_{5} \mathrm{~B}_{3}$ and $\mathrm{Fe}_{2} \mathrm{~B}$ borides. After annealing at $1450 \mathrm{~K}$, the phase decomposition of $\mathrm{Fe}_{5} \mathrm{~B}_{3}$ occurs to form monoboride and $\mathrm{Fe}_{2} \mathrm{~B}$ boride.

Study of microstructure of the alloy with boron content of $10.0 \mathrm{wt} . \%$ shows that the phase composition is represented by $\mathrm{FeB}$ monoboride and $\mathrm{Fe}_{5} \mathrm{~B}_{3}$ and $\mathrm{Fe}_{2} \mathrm{~B}$ borides (Fig. 3, a). Annealing of this alloy at $1473 \mathrm{~K}$ for four hours and further cooling with the rate of $10^{2} \mathrm{~K} / \mathrm{s}$ lead to volume fraction decrease of two-phase regions containing monoborides in $\mathrm{Fe}_{2} \mathrm{~B}$ boride matrix (Fig. 3, a). After annealing, the volume fraction of $\mathrm{Fe}_{5} \mathrm{~B}_{3}$ boride increases due to $\mathrm{FeB}+\mathrm{Fe}_{2} \mathrm{~B} \rightarrow \mathrm{Fe}_{5} \mathrm{~B}_{3}$ transformation in the solid state. In the as-annealed condition diffractogram we observe a considerably declining number of lines 72 
corresponding to $\mathrm{FeB}$ phase. The as-cast microstructure of alloy with boron content of 9.3 wt.\% consists of $\mathrm{FeB}$ monoboride as well as of $\mathrm{Fe}_{2} \mathrm{~B}$ and $\mathrm{Fe}_{5} \mathrm{~B}_{3}$ borides. The occurrence of $\mathrm{FeB}$ monoboride lines in the alloy diffractogram can be explained by $\mathrm{Fe}_{5} \mathrm{~B}_{3}$ phase decomposition with forming $\mathrm{FeB}$ monoboride and $\mathrm{Fe}_{2} \mathrm{~B}$ boride.

Annealing of the alloy with boron content of $9.3 \mathrm{wt} . \%$ leads to the increase in the number of $\mathrm{Fe}_{5} \mathrm{~B}_{3}$ lines in the alloy diffractogram (Fig. 4, b). In addition to this phase, $\mathrm{Fe}_{2} \mathrm{~B}$ boride lines and $\mathrm{FeB}$ monoboride lines are detected. In the as-annealed condition the lines of monoboride phase appear in the diffractogram in a very small quantity. Findings on phase composition of the Fe-B alloy at boron content of 9.0-15.0 wt.\% differ from currently available conceptions mapped in the state diagram of the system [17-18].

The analysis of obtained results reveals that at boron content of 9.0-15.0 wt.\% under crystallization the formation of $\mathrm{Fe}_{5} \mathrm{~B}_{3}$ boride occurs at $1680 \mathrm{~K}$, and at $1420 \mathrm{~K}$ its decomposition into two phase, $\mathrm{Fe}_{2} \mathrm{~B}$ boride and $\mathrm{FeB}$ monoboride, takes place. This is in agreement with the results of previous studies $[12,16]$. Thus, it is shown experimentally that in the Fe-B system alloys in the boron concentration range of $8.8-10.5 \mathrm{wt} . \%$ the eutectic transformation $\mathrm{L} \rightarrow \mathrm{Fe}_{5} \mathrm{~B}_{3}+\mathrm{Fe}_{2} \mathrm{~B}$ occurs. The silicon impurities from amorphous boron are likely to have a very significant effect on the $\mathrm{Fe}_{5} \mathrm{~B}_{3}$ formation. To determine the existence of decomposition, the thermodynamic stability of FeB should be examined.

One of the main factors for controlling the process of phase formation and phase transformation are thermodynamic functions of the phase. But obtaining the values of thermodynamic functions of $\mathrm{FeB}$ monoboride from experimental data faces with certain difficulties. Accounting for the contributions, responsible for the fluctuation processes, in Gibbs energy enables us to determine theoretically the thermodynamic functions of FeB.

To calculate the thermodynamic stability of monoboride, the expression of thermodynamic potential (Gibbs energy) of FeB phase is derived and approach proposed in [16] is used. The Gibbs energy value for pure components and energy of interaction between boron and iron atoms are taken from [19-20]. Then we can write

$$
G_{\mathrm{m}}^{\mathrm{FeB}}=x_{1} G_{1}^{0}+x_{2} G_{2}^{0}+R T\left(x_{1} \ln x_{1}+x_{2} \ln x_{2}\right)+x_{1} x_{2} L_{12}-\frac{L_{12}^{2} x_{1}^{2} x_{2}^{2}}{2 Z T R} .
$$

Here $G_{i}{ }^{0}$ is Gibbs energies of pure components $(\mathrm{J} / \mathrm{mol}), R$ is the universal gas constant $(R=8.31 \mathrm{~J} /(\mathrm{mol} \cdot \mathrm{K})), T$ is temperature $(\mathrm{K}), L_{12}$ is an interaction energy of components $(\mathrm{J} / \mathrm{mol}), Z$ is a coordination number, $Z=4$ for monoboride [1]. The interaction energy $L_{12}$ of elements depends on temperature as $L_{12}=a+b T+c T \ln T$. Using data for the pure components $G_{1}{ }^{0}, G_{2}{ }^{0}$ [19-20] and the energy of interaction between components in the phase from [21-23], we obtain the temperature dependence of Gibbs energy of the melt.

To determine the stability of the phase, let us find a variation of Gibbs energy:

$$
\delta G=\sum_{n=1}^{\infty} \frac{1}{n !}\left[\delta T \frac{\partial}{\partial T}+\delta x_{1} \frac{\partial}{\partial x_{1}}+\delta x_{2} \frac{\partial}{\partial x_{2}}\right]^{n} G .
$$

The general condition of the phase stability by Gibbs is that arbitrary variations of the internal energy and external parameters of a system should not cause both reversible and irreversible processes in the system (so that the system is not out of equilibrium). Therefore, these deviations must be with the property that

$$
\delta U-T \delta S+p \delta V-\mu_{1} \delta x_{1}-\mu_{2} \delta x_{2}>0
$$

(here $S$ is entropy, $p$ is pressure, $V$ is volume, $\mu$ is chemical potential).

Let us expand the Gibbs energy in series for small $\delta T$ and $\delta x_{i}$, taking into account the relation between the internal energy $U$ and Gibbs free energy $U=G+T S-p V$, and then 
take into consideration only the first and the second degree approximation [24]. Then the condition of thermodynamic stability can be written in the form:

$$
\begin{array}{r}
\left(\frac{\partial S}{\partial T}\right)_{x_{1} x_{2}} \delta T^{2}+\left(\frac{\partial \mu_{1}}{\partial x_{1}}\right)_{T x_{2}} \delta x_{1}^{2}+\left(\frac{\partial \mu_{2}}{\partial x_{2}}\right)_{T x_{1}} \delta x_{2}^{2}+2\left(\frac{\partial \mu_{1}}{\partial T}\right)_{x_{1} x_{2}} \delta x_{1} \delta T+ \\
+2\left(\frac{\partial \mu_{2}}{\partial T}\right)_{x_{1} x_{2}} \delta x_{2} \delta T+2\left(\frac{\partial \mu_{2}}{\partial x_{1}}\right)_{T x_{2}} \delta x_{1} \delta x_{2} \geq 0 .
\end{array}
$$

Then we obtain the determinant of stability for FeB monoboride in the form:

$$
D=\left|\begin{array}{lll}
\left(\frac{\partial S}{\partial T}\right)_{x_{1} x_{2}} & \left(\frac{\partial \mu_{1}}{\partial T}\right)_{x_{1} x_{2}} & \left(\frac{\partial \mu_{2}}{\partial T}\right)_{x_{1} x_{2}} \\
\left(\frac{\partial \mu_{1}}{\partial T}\right)_{x_{1} x_{2}} & \left(\frac{\partial \mu_{1}}{\partial x_{1}}\right)_{T x_{2}} & \left(\frac{\partial \mu_{2}}{\partial x_{1}}\right)_{T x_{2}} \\
\left(\frac{\partial \mu_{2}}{\partial T}\right)_{x_{1} x_{2}} & \left(\frac{\partial \mu_{1}}{\partial x_{2}}\right)_{T x_{1}} & \left(\frac{\partial \mu_{2}}{\partial x_{2}}\right)_{T x_{1}}
\end{array}\right|
$$

In order for the phase to be in a state of stable equilibrium, it is necessary that $D$ and all the leading subdeterminants of the matrix of stability are non-negative [20]. Since the determinant (2) of the matrix of stability is greater than zero and the principal minors of the matrix of stability are greater than zero, the iron monoboride within the temperature interval of $1273-1873 \mathrm{~K}$ is thermodynamically stable. As we can see from Fig. 5, the curve of thermodynamic stability at $1423 \mathrm{~K}$ passes through an indistinct minimum. Stability drop with the temperature decrease means that at the microscopic level the formation of a new phase begins. However, the structural changes in monoboride cannot be detected: forming nuclei may differ from the initial phase only by the magnetic moment, which was observed by the authors of [2]. The obtained results enable us to propose a new approach to constructing the state diagram for the Fe-B system and the phase transformations occurring in these alloys.

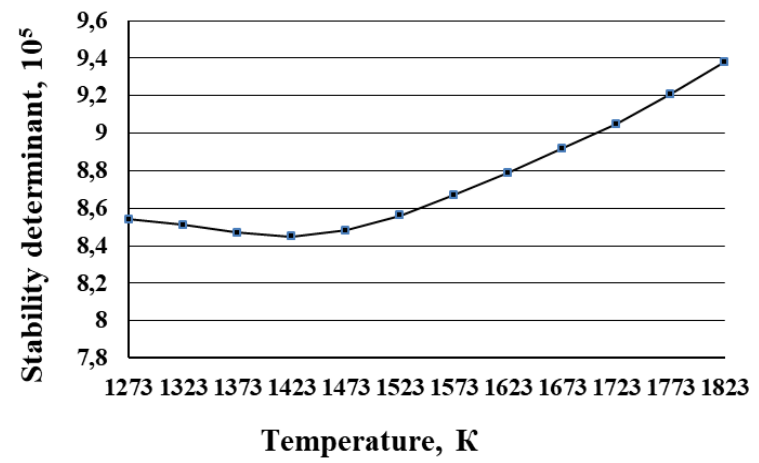

Fig. 5. Temperature dependence of the determinant of thermodynamic stability for FeB monoboride.

According to the findings, in the Fe-B system at $1680 \mathrm{~K}$ and boron concentration of $10.5 \mathrm{wt}$.\% the formation of $\mathrm{Fe}_{5} \mathrm{~B}_{3}$ occurs as a result of peritectic reaction $\mathrm{L}+\mathrm{FeB} \rightarrow \mathrm{Fe}_{5} \mathrm{~B}_{3}$. In the boron concentration range of $8.8-10.5 \mathrm{wt} . \%$ the eutectic transformation $\mathrm{L} \rightarrow \mathrm{Fe}_{5} \mathrm{~B}_{3}+\mathrm{Fe}_{2} \mathrm{~B}$ takes place. This fact is proved by the experimental results given in this paper and is in a good agreement with data of Refs. [9-10]. 
Thus, the phase transformation represented in many state diagrams of the Fe-B system alloys at the temperature of $1420 \mathrm{~K}$ and associated with the polymorphic transformation of the high-temperature $\beta$-FeB monoboride into the low-temperature $\alpha$ $\mathrm{FeB}$ phase can be explained by the phase decomposition of $\mathrm{Fe}_{5} \mathrm{~B}_{3}$ with the formation of $\mathrm{FeB}$ monoboride and borides of $\mathrm{Fe}_{2} \mathrm{~B}: \mathrm{Fe}_{2} \mathrm{~B}-\mathrm{Fe}_{5} \mathrm{~B}_{3} \rightarrow \mathrm{FeB}+\mathrm{Fe}_{2} \mathrm{~B}$.

\section{Conclusions}

In this work it is shown that after the casting, in the alloy structure there is $\mathrm{Fe}_{5} \mathrm{~B}_{3}$ phase, as well as $\mathrm{FeB}$ monoboride and $\mathrm{Fe}_{2} \mathrm{~B}$ boride. It is shown experimentally that at $1680 \mathrm{~K}$ the formation of $\mathrm{Fe}_{5} \mathrm{~B}_{3}$ occurs as a result of peritectic reaction $\mathrm{L}+\mathrm{FeB} \rightarrow \mathrm{Fe}_{5} \mathrm{~B}_{3}$. At the boron content of $8.8-10.5 \mathrm{wt} . \%$ in the $\mathrm{Fe}-\mathrm{B}$ alloys the eutectic transformation $\mathrm{L} \rightarrow \mathrm{Fe}_{5} \mathrm{~B}_{3}+\mathrm{Fe}_{2} \mathrm{~B}$ is likely to take place. At $1420 \mathrm{~K}$ there is the phase decomposition of $\mathrm{Fe}_{5} \mathrm{~B}_{3}$ boride with the formation of $\mathrm{FeB}$ monoboride and $\mathrm{Fe}_{2} \mathrm{~B}$ boride: $\mathrm{Fe}_{5} \mathrm{~B}_{3} \rightarrow \mathrm{FeB}+\mathrm{Fe}_{2} \mathrm{~B}$.

Accounting for the first degree approximation of high-temperature expansion of thermodynamic potential for $\mathrm{FeB}$ iron monoboride in a binary $\mathrm{Fe}-\mathrm{B}$ alloy enables to calculate the temperature dependence of main thermodynamic quantities and to study the thermodynamic stability of the phase. It is shown, that stability drop of $\mathrm{FeB}$ monoboride at $1423 \mathrm{~K}$ allows assuming that at the microlevel the formation of a new phase begins.

Therefore, the obtained results allows to suggest a new approach to the constructing the state diagrams and the phase transformations occurring in the Fe-B alloys.

\section{References}

1. Samsonov, G.V. Fizicheskoie materialovedenie karbidov / G.V. Samsonov, G.Sh. Upadhaya, V.S. Neshpor. - Kiev: Naukova dumka, 1974. - 456 p.

2. Rades, S. Wet-Chemical Synthesis of Nanoscale Iron Boride, XAFS Analysis and Crystallisation to $\alpha-\mathrm{FeB} / \mathrm{S}$. Rades, A. Kornowski, H. Weller, B. Albert // Chemical Physics and Physical Chemistry. - 2011. - Vol. 12, No. 9. - P. 1756 - 1760.

3. Barinov, V.A. Structure and magnetic properties of the $\alpha-\mathrm{FeB}$ phase obtained by mechanical working / V.A. Barinov, G.A. Dorofeev, L.V. Ovechkin et al. // Physics Status Solidi A. - 1991 - Vol. 123, No. 2. - P. 527 - 534.

4. Portnoy, K.I. State diagram of iron-boron system / K.I. Portnoy, M.Kh. Levinskaya, V.M. Romashov // Metal Powder Industry. - 1969. - No. 8(80). P. $66-69$.

5. Filonenko, N.Yu. Effect of carbon on physical and structural properties of FeB iron monoboride / N.Yu. Filonenko, A.N. Galdina // East European Journal of Physics. 2016. - Vol. 3, No. 2. - P. 49 - 53.

6. Filonenko, N.Yu. Effect of carbon on physical and structural properties of $\mathrm{Fe}_{2} \mathrm{~B}$ boride / N.Yu. Filonenko, O.M. Galdina // Physics and Chemistry of Solid State. -2016. Vol. 17, No. 2. - P. $251-255$.

7. Homolova, V. Experimental Study of Phase Composition of Fe-(30-60)B-C alloys and boron-rich corner of Fe-B-C phase diagram / V. Homolova, L. Ciripova , A Vyrostkova // J. Phase Equilib. Diffus. - 2015. - Vol. 36, No. 6. - P. 599 - 605.

8. Filonenko, N.Yu. The effect of carbon on phase composition and phase transformations in Fe-B system alloys / N.Yu. Filonenko, O.Yu. Beryoza, O.G. Bezrukava // Probl. Atom. Sci. Tech. - 2013. - No. 5(87). - P. 168 - 172.

9. Kneeller, E. The phase $\mathrm{Fe}_{2} \mathrm{~B} /$ E. Kneeller, Y. Khan. // Z. Metallkd. - 1987. Bd. 78, nr. 12. - S. $825-835$. 
10. Van Ende, M.-A. Critical thermodynamic evaluation and optimization of the $\mathrm{Fe}-\mathrm{B}, \mathrm{Fe}-\mathrm{Nd}, \mathrm{B}-\mathrm{Nd}$ and Nd-Fe-B systems / M.-A. Van Ende, I.-H. Jung // Journal of Alloys and Compounds. - 2013. - Vol. 548. - P. 133 - 154.

11. Faria, M.I.S.T. Microstructural characterization of as-cast Co-B alloys / M.I.S.T. Faria, T. Leonardi, Gilberto Carvalho Coelho, Carlos Angelo Nunes, Roberto Ribeiro de Avillez // Materials Characterization. - 2006. - Vol. 58, No. 4. - P. 358 - 362.

12. Filonenko, N.Yu. Doslidzhennya fazovykh peretvoren ta fazovogo skladu splaviv systemy Fe-B / N.Yu. Filonenko, O.Yu. Beryoza, O.G. Bezrukava // Metallofizika i Noveishie Tekhnologii. - 2013. - Vol. 35, No. 8. - P. 1101 - 1107.

13. Spiridonova, I.M. Structure and peculiarities of $\mathrm{Fe}(\mathrm{B}, \mathrm{C})$ crystals / I.M. Spiridonova, E.V. Sukhovaya, V.P. Balakin // Metallurgia. - 1996. - Vol. 35, No. 2. - P. $65-68$.

14. Kuzma, Yu.B. Kristallokhimiya boridov / Yu.B. Kuzma. - Kyiv: Vyshcha shkola, 1983. - $159 \mathrm{p}$.

15. Shubert, K. Kristallicheskie struktury dvukhkomponentnykh faz / K. Shubert. M.: Metallurgia, 1971. - $532 \mathrm{p}$.

16. Filonenko, N.Yu. Investigation of Formation Mechanism and Thermodynamic Functions of $\mathrm{Fe}_{5} \mathrm{~B}_{3}$ Iron Boride / N.Yu. Filonenko, A.N. Galdina // Proc. IEEE Intern. Conf. on Nanomaterials: Application and Properties. - 2017. - Vol. 6 (3). - 003NNSA25.

17. Kuzma, Yu.B. Dvoynyie i troynyie sistemy, soderzhashchiye bor: Spravochnik / Yu.B. Kuzma, P.F. Chaban. - M.: Metallurgiya, 1990. -320 p.

18. Lyakishev, N.P. Diagrammy sostoyaniya dvoynykh metallicheskikh sistem: Spravochnik. Vol. 3, book 1 / N.P. Lyakishev. - M.: Mashinostroenie, 2001. - 498 p.

19. Roble, R.A. Thermodynamic Properties of Minerals and Related Substances at $298.15^{\circ} \mathrm{K}\left(25.0^{\circ} \mathrm{C}\right)$ and One Atmosphere $(1.013$ Bars $)$ Pressure and at Higher Temperatures / R.A. Roble, D.R. Waldbaum. - Orton Memorial Library of the Ohio State University, 1970. $-262 \mathrm{p}$.

20. Dinsdale, A.T. SGTE data for pure elements / A.T. Dinsdale // NPL Materials Centre, Division of Industry and Innovation, National Physical Laboratory, Teddington, Middlesex, TW11 0LW, UK. - 1991. - 174 p.

21. Halemans, B. Thermodynamic reassessment and calculation of the Fe-B phase diagram / B. Halemans, P. Wollemans, J.R. Roos // Z. Metallkd. - 1994. -Vol. 85, No. 10. - P. $676-682$.

22. Van Rompaey, T. Thermodynamic optimization of the B-Fe system / T. Van Rompaey, K.C. Kumar, P. Wollants // Journal of Alloys and Compounds. - 2002. - Vol. 334. - P. 173 - 181.

23. Palumbo, M. Driving forces for crystal nucleation in Fe-B liquid and amorphous alloys / M. Palumbo, G. Cacciamani, E. Bosco, M. Baricco // Intermetallics. 2003. - No. 11. - P. 1293 - 1299.

24. Soldatova, E.D. Stability conditions for the basic thermodynamic potentials and substantiation of the phase diagrams / E.D. Soldatova // Journal of Molecular Liqiuds. 2006. - Vol. 127, Issues 1-3. - P. $603-616$. 